\title{
Review of fuzzy techniques in maritime shipping operations
}

\author{
Jana Ries ${ }^{1}$, Rosa G. González-Ramírez ${ }^{2}$, Stefan Voß ${ }^{3}$ \\ 1 Portsmouth Business School, University of Portsmouth, Portland Street, \\ Portsmouth, PO1 3DE, UK \\ 2 Faculty of Engineering and Applied Sciences, Universidad de Los Andes, Chile. \\ Monsenor Alvaro Portillo 12450, Santiago, Chile \\ 3 Institute of Information Systems, University of Hamburg, Von-Melle-Park 5, \\ Hamburg, 20146, Germany \\ jana.ries@port.ac.uk, rgonzalez@uandes.cl, stefan.voss@uni-hamburg.de
}

\begin{abstract}
Fuzzy Logic has found significant interest in the context of global shipping networks due to its applicability to uncertain decision making environments. Its use has been particularly important when solving location and equipment selection problems. While being applicable as a stand-alone technique, Fuzzy Logic has become increasingly interesting as an added feature within classic Operational Research techniques. This paper gives an outline of the methodological relevance of Fuzzy Logic at a strategic, tactical and operational level for maritime operations. In addition, a general classification of decision problems in maritime logistics is presented, extending previous classifications in the literature to the wider context of multiple port networks.
\end{abstract}

Keywords: Fuzzy Logic, Hybrid techniques, Maritime shipping, Container terminals.

\section{Introduction}

While the literature on solving decision problems in maritime operations spans over the diverse field of operational research (Steenken et al. 2004, Stahlbock and Voß 2008, Böse 2011), Multi-Critieria Decision Making (MCDM) forms an integral part by enabling the simultaneous or sequential consideration of multiple objectives or a range of criteria. According to Hwang and Yoon (1981), MCDM techniques can be classified into two main sets, multi-objective decision making $(\mathrm{MODM})$ and multi-attribute decision making (MADM). The latter are applied to the ranking, selection or sorting of multi-dimensional alternatives. In maritime shipping, relevant MADM approaches found in the literature are Analytic Hierarchy Process (AHP) introduced by Saaty (1977), Elimination and Choice Expressing Reality (ELECTRE), (Benayoun et al., 1966), Techniques for Preference by Similarity to the Ideal Solution (TOPSIS), (Hwang and Yoon, 1981), and Evidential Reasoning and Fuzzy Logic (Zadeh, 1965). The latter has been 
specifically designed to address imprecision and uncertainty in decision problems. It is based on the use of fuzzy set theory which considers the association of linguistic terms with crisp numerical input. In combination with a rule base, it is referred to as a fuzzy inference system (FIS). In contrast to Fuzzy Logic, traditional MCDM techniques are generally challenged by the inability to address uncertainty with respect to imprecise information which has led to an increasing interest in applying Fuzzy Logic across multiple disciplines.

One of the key reasons for applying Fuzzy Logic in decision making are the existence of fuzziness in the information, rather than randomness in the problem context (Riedewald, 2011). Moreover, the author states that the non-existence of a suitable probability distribution or difficulties in obtaining one, as well as the availability of vague expert information are underpinning the suitability of Fuzzy Logic.

An increasing interest is observed, particularly, in embedding or combining fuzzy set theory into traditional strategies to address real-life uncertainty, e.g. in the problem context of maritime shipping. Hereby, the integration of Fuzzy Logic is distinguished into three concepts, namely classic stand-alone Fuzzy Logic approaches, embedded techniques and hybrid strategies. While stand-alone approaches are predominantly using fuzzy inference systems, embedded fuzzy techniques extend classic operational research strategies by featuring a fuzzy aspect within the problem formulation or the solution approach. Hybrid approaches use the combination of an FIS or embedded fuzzy techniques in combination with traditional non-fuzzy stand-alone approaches.

The goal of this paper is to provide a comprehensive review of decision making stages incorporating Fuzzy Logic to address maritime operations. To our best knowledge, this is the first review of its kind in this sector. The remainder of the paper is organized as follows. A classification of decision problems in maritime oprerations is introduced in Section 2. A review of literature studies that are investigated using a fuzzy philosophy in the context of a single port and a multiple port network are presented in Section 3 and 4, respectively. Section 5 outlines a classification of proposed solution approaches using Fuzzy Logic and Section 6 outlines concluding remarks.

\section{Decision Making in Maritime Operations}

Over the years, international trade has significantly increased its volumes supported by national and international efforts from governments and private organiszations. Investments in transport infrastructure and technology have also facilitated the exchange of goods in this global environment. However, a significant effort in ensuring competitiveness to allow for ongoing economic growth is required. International trade involves a great number of stakeholders both public and private interacting in global supply chains. The different interactions of stakeholders and the different procedures that need to be undertaken imply very complex procedures and operations at the different echelons of the port supply chain network. This also implies higher levels of uncertainty and variability. 
Maritime transport accounts for the highest participation of worldwide foreign trade requiring an efficient maritime shipping network configuration as well as efficient cargo handling at each node of the network. Moreover, maritime ports form strategic nodes within global supply chain networks providing intermodal facilities and hence taking a more active role with respect to transshipments as well as the integration of their hinterland and foreland.

The decision making problems that arise in maritime operations have been classified into two main categories: problems that arise within a single container port and problems that arise within a network of muliple ports and other related terminals (e.g. depots, warehouses, etc.). Furthermore, decisions are also classified based on the decision level and the layout functions of the terminal (seaside, yard, gate). Bierwirth and Meisel (2010) provide a classification of problems at a container terminal focussing on strategic and operational aspects. Figure 1 uses an extended categorisation for the decision level by extending the set of strategic and operational decision problems to tactial ones. The key feature to differentiate between the individual sets of problems is the underlying time horizon. While no integrating links have been identified in the presented problem classification as done by Bierwirth and Meisel (2010), a broader view has been undertaken with the assumption that all problems are somewhat interlinked within a system that operates as integrated as a port. Furthermore, port networks have been considered with regards to decision making within the shipping network (seaside) and the hinterland network (landside).

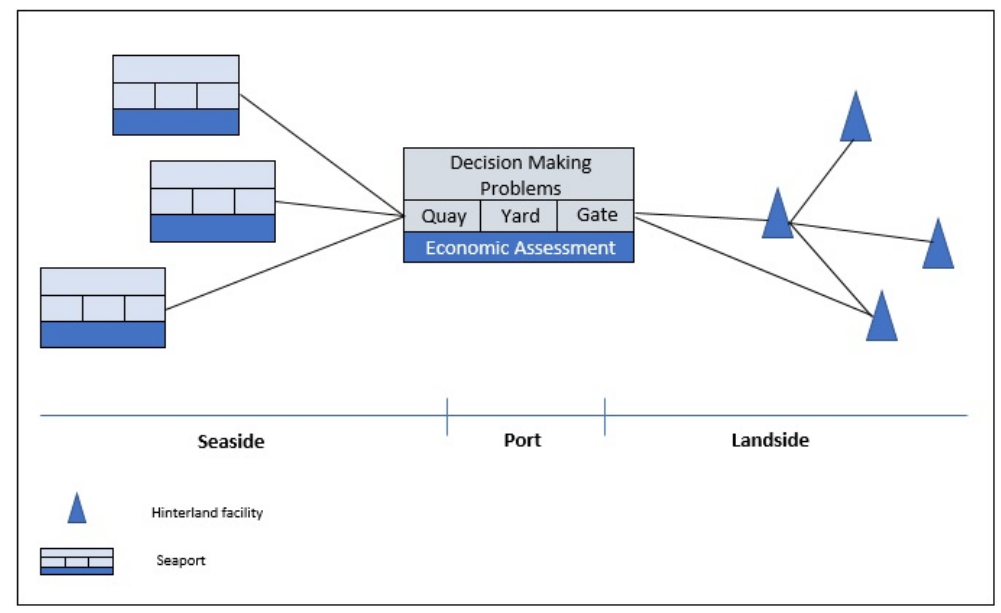

Fig. 1. Multiple Port Network (MPN) structure

Figure 2 illustrates the classification of decision making problems within a single container port or a network of container ports. Management evaluation and assessment tools have been considered in the review. Figure 3 outlines relevant assessment strategies, including maritime-specific considerations. 


\begin{tabular}{|c|c|c|c|}
\hline Decision level & Seaside & Yard & Gate/Landside/Hinterland \\
\hline Strategic & \multicolumn{3}{|c|}{ Choice of Location, Equipment Selection, Layout and Network Design } \\
\hline \multirow{4}{*}{ Tactical } & Tactical Berth Allocation & Tactical Storage Space Allocation & Tactical Gate Capacity Planning \\
\hline & \multirow{3}{*}{$\begin{array}{c}\text { Ship Routing and Fleet } \\
\text { Design }\end{array}$} & $\begin{array}{c}\text { Empty Container Inventory } \\
\text { Management }\end{array}$ & Truck Arrival Forecasting \\
\hline & & \multirow{2}{*}{ Dispatching Policy Design } & Rail Transport Planning \\
\hline & & & Container Dwell Analysis \\
\hline \multirow{5}{*}{ Operational } & Berth Allocation & $\begin{array}{c}\text { Storage Space Allocation and } \\
\text { Container Stacking }\end{array}$ & \multirow{2}{*}{ Gate Management } \\
\hline & $\begin{array}{l}\text { Quay Crane Assignment } \\
\text { (Crane split) }\end{array}$ & $\begin{array}{l}\text { Block Relocation \& Marshalling } \\
\text { Problems } \\
\end{array}$ & \\
\hline & $\begin{array}{l}\text { Quay Crane Scheduling } \\
\text { (Crane split) }\end{array}$ & Transportation Planning & \multirow{3}{*}{ Inter-Terminal Transport Planning and Scheduling } \\
\hline & Stowage Planning & Empty Container Management & \\
\hline & \multicolumn{2}{|c|}{ Resource Planning and Scheduling } & \\
\hline
\end{tabular}

Fig. 2. Decision Making Classification - adapted from Bierwirth and Meisel (2010)

\begin{tabular}{|c|c|}
\hline General Management & Maritime Specific Evaluation \\
\hline Risk Management & Competitiveness Analysis \\
\hline Knowledge Management & Shipping Analysis \\
\hline Human Resource Management & Port Development \\
\hline \multicolumn{2}{|c|}{ Performance Evaluation } \\
\hline
\end{tabular}

Fig. 3. Economic Assessment techniques 


\section{$3 \quad$ Fuzzy Decision making within a container port}

This section reviews existing studies in the context of decision making within container ports that use Fuzzy Logic to aid the modelling or solving strategy. The aim is to underpin the diverse applicability of Fuzzy Logic and to identify patterns with regards to the technique being suitable to particular problem structures.

\subsection{Seaside decision making}

At the seaside, fuzzy decision making has been predominantly considered for berth allocation and quay crane management. Hereby, the use of fuzzy techniques was introduced in studies for the berth allocation problem, see Lokuge et al. (2004), Lokuge and Alahakoon (2007), and Zhou et al. (2006). Furthermore, Vukadinovíc and Teodorovíc (1994) address berth allocation problems in the context of river ports introducing a fuzzy strategy to decide the number of operated barges at river ports. In the context of quay crane assignment and scheduling problems, Fuzzy Logic has been applied in selecting suitable equipment (Chao and Lin, 2011), automating quay crane operations (Yasunobu and Hasegawa, 1986; Liu et al., 2005) and the classic quay crane scheduling problem (Chung and Chan, 2013).

Taking an integrating approach, Exposito-Izquierdo et al. (2016) proposed fuzzy optimization models to take interdependencies of seaside decisions such as quay crane scheduling and the berth allocation problem into consideration.

\subsection{Yard and Gate decision making}

Similarly to the seaside operations, decisions in the yard have been addressed in the context of yard equipment and truck scheduling ( $\mathrm{Ng}$ and Ge, 2006). Moreover, Fuzzy Logic has been applied to container handling (Jin et al., 2004 and Seyed-Hosseini et al., 2009), the management of handling and storage equipment (Homayouni and Tang, 2015), and truck or railyard dispatching (Yu and Zhang 2010, He et al. 2000). Kim et al. (2007) and Ries et al. (2014) apply Fuzzy Logic in the context of real-time decision making for container stacking policies, while Zheng et al. (2015) discuss the container loading problem from a multi-objective point of view. Valdés-González et al. (2014) propose an intelligent system for container stacking based on a Fuzzy Logic model, considering the case of the Port of Valparaiso in Chile.

On a strategic level, Fuzzy Logic has been applied to the selection of the most suitable equipment, i.e. yard cranes (Nooramin et al., 2012) at the gate.

\subsection{Economic Assessment}

Within a single port, economic assessment studies that employ Fuzzy Logic methodologies can be distinguished into the following General Management areas: 
Port Performance and Forecasting

Park and Yeo (2012) and Chiu et al. (2014) propose a framework of evaluation for environmental sustainability. Duru et al. (2010) propose a bivariate long term fuzzy inference system to forecasting dry cargo freight rates. The service requirements of a dedicated container terminal is evaluated by a fuzzy analytic hierarchy process model by Hsu et al. (2015). The performance of container handling operations in the BIK container terminal has been analyzed by Jafari et al. (2013). They employ a Fuzzy TOPSIS approach. Gaonkar et al. (2011) model the decisive factors that affect transportation systems in the form of linguistic variables and perform a subjective operational reliability assessment. The authors extend their work by further proposing two fuzzy reliability models to model the uncertainty in estimating vessel's travel time (Gaonkar et al., 2013).

Risk assessment

Risk assessment studies in the literature mainly investigate the well-known high level of uncertainty in the context of maritime shipping and its impact on container yard operations (Yang et al., 2009; Ding and Chou, 2012; Gaonkar et al., 2013; John et al., 2014; Mabrouki et al., 2014). However, some studies show a focus on the aspect of safety including terror threats (Yang et al., 2014) and the operational risk of a ship at sea due to, e.g., weather conditions (Balmat et al. 2009, Balmat et al. 2011). Saeidi et al. (2013) propose the application of a fuzzy TOPSIS approach for container terminal risk assessment.

Information systems and technology evaluations

The business intelligence competencies of a port community system (PCS) in the organizations is evaluated by a fuzzy TOPSIS technique that employ fuzzy weights of the criteria and fuzzy judgements of the PCS to compute the evaluation scores and rankings by Ghazanfari et al. (2014). This framework can be used by ports to support decisions related to the selection of the requirements and attributes for implementing a PCS.

Knowledge and Human Resource Management

A different perspective is presented by Ung et al. (2006) who assess the impact of human error in the context of cargo handling in ports. Liang et al. (2012) have studied the integration of knowledge management into port operations.

\section{Fuzzy Decision making in Port Networks}

Following up on the overview of studies using Fuzzy Logic for a single port, this section reviews existing literature for port networks that have applied Fuzzy Logic. Fuzzy contributions for decision making at the seaside are mainly associated with tactical and operational decision levels, while fuzzy contributions related to the hinterland are predominantly of strategic nature.

\subsection{Seaside decision making}

The main class of problems that has been addressed using Fuzzy Logic at the strategic level is port selection. Chou (2007, 2010), Onut et al. (2011), Yeo et al. 
(2014), Wang et al. (2014), Ergin et al. (2015), Zavadskas et al. (2015) address the port selection problem for a set of existing transshipment port locations, container ports, deep water ports and bunkering ports. In an extension to analysing relevant economic criteria, Chou et al. (2010b) demonstrate the flexibility of Fuzzy Logic in a multi-criteria context such as selection problems by considering other criteria such as port facility conditions and volume of containers when evaluating the suitability of a port in an extension to their initial work.

The tactical and operational decisions in which fuzzy methodologies have been employed at the seaside for a MPN can be distinguished into the following key areas:

\section{Empty container logistics}

Chou (2009), Chou et al. (2010a) and Wang (2007) address the empty container location problem aiming to determine optimal numbers of empty containers at a port or between ports, focussing on the repositioning operations of containers. Tuljak-Suban and Twrdy (2015) propose a fuzzy multicriteria algorithm to evaluate the impact that the global crisis has on the number of excess empty containers at the terminals.

Network design

Network design has been addressed by Chou (2010) whereby an evaluation of existing transshipment port locations is used to decide upon the planned setup of a new transshipment port. Wibowo and Deng (2011) propose a decision support system for the ship selection problem, in which cargo shipping tasks are allocated to ships. They propose a rule based approach and the weighting process is modelled as a fuzzy knowledge base.

\section{Ship fleet routing}

With regards to shipping management, Chuang et al. (2010) investigate ship routing taking into consideration economic and operational parameters, while Wibowo and Deng (2010) consider the case of ship selection studying in particular the setting of criteria weights.

\subsection{Hinterland decision making}

On a strategic level, various decisions have been addressed using the concept of Fuzzy Logic, affecting the hinterland from a MPN perspective. Similarly to the location studies in the context of MPN seaside decisions, the literature shows the relevance of Fuzzy Logic in the selection of dry port and intermodal hub locations by Ka (2011) and Kayikci (2011), respectively. With regards to layout design, the work by Mi and Cheng (2013) investigates the layout of a container centre station by determining the number of lanes at the gate of a railway container centre. Finally, cargo allocation to ports has been investigated by Wanke and Bastos Falcão, (2017) who provide an assessment of the cargo allocation patterns to the

ports of Brazil. This has several policy implications such as, e.g., investments in the development of logistics corridors. 


\subsection{Port performance and efficiency}

The majority of assessment studies take a maritime specific view, including competitiveness analyses of ports and shipping companies, and port development studies in combination with port performance evaluations. Ha et al., (2017) provide a hybrid multi-stakeholder framework for modelling port performance indicators. They define port performance indicators based on the interests and evaluations of several stakeholders of the port using a fuzzy rule-based algorithm and a utility technique. Another topic of interest in the literature is related to the efficiency of a port as discussed by Chao (2017) who provide a multi-stage data envelopment analysis model to evaluate the efficiency of global liner shipping companies. A fuzzy analytical hierarchical process is employed to prioritize the stages. Cho et al. (2007) propose the design of benchmarks for improving container port performance and analyse best practices in this matter. Liu et al. (2009) focus specifically on the aspect of agility in container terminal operations and maritime shipping companies.

In analysing competitiveness and using an evaluative strategy, Ran et al. (2008) and Denisis (2009) investigate the economic strength of container sea shipping, while Yeo and Song (2006) and Celik et al. (2009) investigate the competitiveness of a set of container ports. Within a more generall scope, the competitiveness of Taiwan's free trade ports is analysed by Chen et al. (2016).

Considering a supply chain perspective, Shao et al., (2016) propose a performance evaluation index system for the port supply chain. Their proposal is based on a balanced scorecard framework, and the evaluation model is constructed using a fuzzy-matter-element analysis.

Overall, Fuzzy Logic is shown to be of relevance in particular with regards to context-specific location and selection problems, as well as economic assessment studies.

\section{Fuzzy strategy classification}

In contrast to the previous section, the following classification distinguishes the fuzzy techniques in decision making for maritime shipping into stand-alone approaches, embedded and hybrid designs. The latter two groups make use of a range of operational research methods including meta-heuristics, mathematical programming, queueing theory and statistical techniques.

\subsection{Stand-alone Fuzzy Logic approaches}

In maritime shipping, Fuzzy Logic has been applied in different ways depending on the problem at hand. Vukadinovi and Teodori (1994) introduce a fuzzy strategy to decide on the number of operated barges at river ports. Wibowo and Deng (2011) consider the decision of the type of cargo ship given a particular operational task, while Liu et al. (2005) propose an adaptive control strategy that supports the selection of most suitable quay crane technology. Similarly, 
Chou (2007) addresses the selection of transshipment ports from an economic perspective, while Chou (2010) considers the hub location selection problem for shipping liners. All the aforementioned studies focus on selection problems designed to handle equipment and develop strategies based on solving the port selection problem.

\subsection{Embedded Fuzzy Logic strategies}

The main driver of AHP is the comparison between two criteria instead of assessing an overall set of criteria combined (Saaty 2000). Analytical Network Processing (ANP) can be seen as an extension of AHP utilizing a network for the consideration of critera, alternatives and goals instead of a hierarchy to integrate dependencies. Drawbacks of AHP include the occurrence of rank reversal, the potential extensive lengths of comparisons needed and the potential limitations of the used preference scale. The latter aspect is partially addressed by Fuzzy AHP (FAHP) which embeds the concept of fuzzy numbers into the assessment of decision maker comparisons, see e.g. Torfi et al. (2010). FAHP has been addressed by various performance evaluation studies including the modelling of green operation performance for ports by Chiu et al. (2014). A comparison of AHP and FAHP is found in Nooramin et al. (2012) on the equipment selection problem for yard cranes. The study showed that given the data provided by decision makers and experts, both approaches did not contradict each other and result in similar conclusions. Onut et al. (2011) apply FANP to the port selection problem based on a range of quantitative and qualitative criteria with the latter being modeled using Fuzzy sets. Ko (2009) applies FAHP to the selection of intermodal transport routes across countries with respect to, for example, interconnections, interoperability and legal frameworks.

TOPSIS belongs to the set of MCDA techniques which aims to identify the best alternative by means of evaluating the (Euclidean) distance to the positiveideal (or ideal solution) and negative-ideal solutions, also referred to as Nadir point. While the required subjective input is limited, the main required information needed is the set of criteria-specific weights. Similar to FAHP, Fuzzy TOPSIS uses fuzzy numbers to transform performance rankings with the aim to overcome imprecise information. Ghazanfari et al. (2014) use the fuzzy TOPSIS technique to evaluate the business intelligence competencies of PCSs. Saeidi et al. (2013) proposed the application of a fuzzy TOPSIS approach for container terminal risk assessment. The performance of container handling operations in the BIK container terminal by a fuzzy TOPSIS approach is proposed by Jafari et al. (2013).

Heuristic and meta-heuristic strategies are popular concepts when addressing combinatorial optimization problems providing good solutions in reasonable time. In the problem-specific context of maritime shipping, Genetic Algorithms (GA) were found to be a prominent choice. Fuzzy Logic can be incorporated into a GA framework in different ways. Fuzzy control is one approach to the reactive strategy of parameter control during a run of a GA (Chung and Chan, 
2013, Homayouni and Tang, 2015). Alternatively, Fuzzy Logic may be incorporated by applying fuzzy set theory to model input parameters dealing with any associated imprecision (Chuang et al., 2010).

Mathematical programming is a set of optimization techniques that are based on the structure of the model. It has been applied to the port allocation problem in combination with fuzzy set theory in a two-stage model addressing the demand split and final port destination (Chou et al. 2010b). The authors further address the empty container allocation problem using a fuzzy inventory model by applying fuzzy set theory to the input parameters, and solving it by means of the Kuhn Tucker conditions (Chou 2009, Chou et al., 2010a). Wang (2006) approaches the empty container allocation problem considering a mathematical programming approach incorporating dynamic, stochastic and fuzzy features. Seyed-Hosseini et al. (2009) propose a fuzzy mathematical programming model for the yard allocation problem. Valdés-González et al. (2014) propose a nonlinear optimization problem in combination with a Fuzzy Logic system for the container stacking problem.

Agent-based models apply simulation to a network of interacting entities. In the context of maritime shipping BDI (Beliefs, Desires and Intention) agents have been applied in combination with fuzzy set theory to model fuzzy beliefs. For example, Lokuge et al. (2004) introduce a Adaptive Neuro Fuzzy Inference System (ANFIS) in the context of berth allocation. In an approach to solve the truck dispatching problem, an agent-based model is proposed in combination with a Fuzzy Contract Net Protocol (Fuzzy CNP) by Yu and Zhang (2010).

Mi and Cheng (2013) incorporate fuzzy set theory into the development of a queuing model to address the search for the number of lanes at the door of the domestic railway container centre station.

DELPHI provides a set of techniques to organize the communication process within a group in order to comprehend a complex problem. Wang et al. (2014) apply a combination of Delphi in combination with a fuzzy component that is used for the understanding of key performance indicators (KPI) within ports and Fuzzy TOPSIS to address the selection of bunkering ports for liner shipping companies. Cho et al. (2007) apply DELPHI in combination with FAHP to conduct a performance assessment of ports on the case of the Busan container terminal.

\subsection{Hybrid Fuzzy Logic strategies}

Kayikci (2010) apply the combination of Artificial Neural Networks (ANN) together with FAHP to the facility location problem for intermodal freight logistics centres.

Other MCDA techniques that are applied in maritime shipping decision making are ELECTRE and Evidential Reasoning. ELECTRE is a family of MCDA techniques and was first mentioned in Benayoun et al. (1966) although Bernard Ron is widely known as the "father" of ELECTRE. It consists of two main stages, namely the development of outranking relations and an exploitation procedure. 
Both stages depend on the problem at hand; sorting, ranking or choosing. Similarly to TOPSIS, ELECTRE requires less subjective information which given the non-required pairwise comparisons enables the consideration of a more extensive set of criteria. In the literature, ELECTRE frameworks incorporating fuzzy set theory can be found. However, this combination has not been applied in maritime shipping. Instead Ka (2011) applied the combination of ELECTRE and FAHP to the dry port location selection.

Factor analysis aims to understand the structure of multiple variables. This has been applied in the evaluation of green operations in a selection of a set of Korean ports together with a FIS in order to identify significant evaluating factors and identify a corresponding ranking of the considered ports, respectively (Park and Yeo, 2012). Similarly, Chao and Lin (2011) develop a decision support system to select quay crane technology by identifying relevant criteria using exploratory factor analysis followed by a FIS to initiate the selection.

A SWOT analysis is used to outline and analyse the Strengths, Weaknesses, Opportunities and Threats for an entity, concept or process. The economic feasibility of short sea shipping is investigated on the basis of a SWOT analysis together with the design of a fuzzy inference system to estimate site-specific costing by Denisis (2009). Liang et al. (2012) apply Fuzzy Logic in combination with Quality Function Deployment to prioritize knowledge management solutions.

\section{Concluding Remarks}

Fuzzy Logic has received substantial attention in addressing decision making in maritime shipping on the strategic, tactical and operational level. Its use has found particular importance in addressing location or equipment selection problems as well as suitable space selection for yard operations. In addition, it is possible to observe that Fuzzy Logic methodologies have been widely applied in economic assessment contributions such as port performance and efficiency, as well as risk management. From the perspective of a MPN, few contributions are found in which the port supply chain have been analysed under a more systemic vision. Neither inter-terminal transportation problems and truck drayage operations, nor the design and assessment of coordination mechanisms such as Truck appointment systems have been addressed in the literature using fuzzy techniques. Given the dynamic operations and the fact that huge numbers of stakeholders are employed, port performance indicators for landside productivity analysis can be developed using a Fuzzy Logic approach, such as the Fuzzy AHP and agent-based models to capture the interactions of the different stakeholders.

The key emerging research direction that has found increasing interest with the research community in maritime decision making is the increase of integration by developing solving strategies to address problems simultaneously. In practice, container terminal managers do not solve each problem individually and there are important trade-offs and interactions that have to be considered 
by the decision makers. Based on the papers reviewed, only Exposito-Izquierdo et al. (2016) address an integrated problem of berth allocation and quay crane scheduling implementing a fuzzy element. From the perspective of shipping line companies, some contributions can be found in terms of evaluating the efficiency of operations and empty container repositioning problems. However, in terms of fleet deployment and ship routing and scheduling, no contributions using Fuzzy Logic techniques are found in the literature.

The movement of containers between terminals and typically drayage operations is referred as the inter-terminal transportation problem (Tierney et al., 2014). None of the contributions in the literature has applied Fuzzy Logic techniques, representing a potential area for research as some of the decisions related to assignment of equipment and priorities may have fuzzy components. Other related problems focused on the coordination of truck arrivals at the gate of the port terminals have been also studied in the literature but none has applied Fuzzy Logic techniques in their analysis (Giuliano and Obrien, 2007; Zehendner and Feillet, 2014).

Another research gap that could be identified is related to the container stacking problems which is characterised by a high level of uncertainty which leads to a trade-off between the planning horizon and the risk of disruptions. Import containers, for example, may be assigned variable dwell times which makes it hard to determine the best location to reduce rehandles. Few contributions are found in the literature dealing with this type of problems using Fuzzy Logic.

In the same line of new technologies and the era of digitalization, further analysis can be studied in terms of evaluating the impacts of information systems such as PCS for the electronic data interchange. Furthermore, protocols such as blockchain and the use of sensors and IoT to support the business processes of ports and the exchange of information can be evaluated to estimate benefits and derive recommendations. In this regard, the use of Fuzzy Logic techniques to account for different factors and perspectives can be very useful.

In summary, the literature has shown that while Fuzzy Logic can address a problem in form of a stand-alone approach, it was shown that Fuzzy Logic has gained more importance when being integrated into well-performing operational research techniques within a highly dynamic environment such as port networks.

Being provocative, one can conclude that mainstream combinatorial optimization problem solving and Fuzzy Logic have not yet really found each other. Both sides seem not to utilise the other with appropriate recognition in turn. To overcome this situation is the most important future issue in this realm.

\section{References}

1. J.-F. Balmat, L. Frédéric, R. Maifret, and N. Pessel. Maritime risk assessment (marisa), a fuzzy approach to define an individual ship risk factor. Ocean Engineering, 36:1278-1286, 2009.

2. J.-F. Balmat, L. Frédéric, R. Maifret, and N. Pessel. A decision-making system to maritime risk assessment. Ocean Engineering, 38:171-176, 2011. 
3. R. Benayoun, B. Roy, and B. Sussman. Electre: une méthode pour guider le choix en présence des point de vue multiples. Technical report, 1966.

4. C. Bierwirth and F. Meisel. A survey of berth allocation and quay crane scheduling problems in container terminals. European Journal of Operations Research, 202:615-627, 2010.

5. J.W. Böse. Operations research/computer science interfaces series. In Handbook of terminal planning. Springer, New York/Heidelberg, 2011.

6. M. Celik, S. Cebi, C. Kahraman, and I.D. Er. Application of axiomatic design and topsis methodologies uner fuzzy environment for proposing competitive strategies on turkish container ports in maritime transportation network. Expert Systems with Applications, 36:4541-4557, 2009.

7. S.-L. Chao. Integrating multi-stage data envelopment analysis and a fuzzy analytical hierarchical process to evaluate the efficiency of major global liner shipping companies. Maritime Policy $\& 5$ Management, pages 1-16, 2017.

8. S.-L. Chao and Y.-J. Lin. Evaluating advanced quay cranes in container terminals. Transport Researc Part E: Logistics and Transportation Review, 47(4):432-445, 2011.

9. Chun-An Chen, Yi-Hui Chiang, Tzu-Kuang Hsu, and Jung-Wen Hsia. Strategies to increase the competitiveness of taiwans free trade ports based on the fuzzy importance-performance analysis. Asian Economic and Financial Review, 6(11):681, 2016.

10. R.-H. Chiu, L.-H. Lin, and S.-C. Ting. Evaluation of green port factors and performance: A fuzzy ahp analysis. Mathematical Problems in Engineering, 2014.

11. G.-S. Cho, H.-S. Hwang, and K.-W. Lee. A performance analysis framework for the container terminals by dhp method. In International Conference on Intelligent Manufacturing and Logistics Systems IML, Kitakyushu, Japan, 2007.

12. C.-C. Chou. A fuzzy mcdm method for solving marine transshipment container port selection problems. Applied Mathematics and Computation, 186:435-444, 2007.

13. C.-C. Chou. Application of FMCDM model to selecting the hub location in the marine transportation: A case study in southeastern asia. Mathematical and Computer Modelling, 51:791-801, 2010.

14. C.C. Chou. A fuzzy backorder inventory model and application to determining the optimal empty-container quantity at a port. International Journal of Innovative Computing, Innovation and Control, 5:4825-4824, 2009.

15. C.C. Chou, R.-H. Gou, C.-L. Tsai, C.-P. Tsou, M.-C. ad Wong, and H.-L. Yu. Application of a mixed fuzzy decision making and optimization programming model to the empty container allocation. Applied Soft Computing, 10:1071-1079, 2010a.

16. C.C. Chou, F.-T. Kuo, R.-H. Gou, Tsao. C.-L., C.-P. Wong, and M.-C. Tsou. Application of a combined fuzzy multiple criteria decision making and optimization programming model to the container transportation demand split. Applied Soft Computing, 10:1080-1086, 2010b.

17. T.-N. Chuang, C.-T. Lin, J.-Y. Kung, and M.-D. Lin. Planning the route of container ships: A fuzzy genetic approach. Expert Systems with Applications, 37:29482956, 2010.

18. S.H. Chung and F.T.S. Chan. A workload balancing genetic algorithm for the quay crane scheduling problem. International Journal of Production Research, 51, 2013.

19. A. Denisis. An economic feasibility study of short sea shipping including the estimation of externalities with fuzzy logic. PhD thesis, University of Michigan, 2009. 
20. J.F. Ding and Chien-Chang Chou. A fuzzy mcdm model to evaluate investment risk of location selection for container terminals. WSEAS Transactions on Information Science and Applications, 9(10):295-304, 2012.

21. O. Duru, E. Bulut, and S. Yoshid. Bivariate long term fuzzy time series forecasting of dry cargo freight rates. The Asian Journal of Shipping and Logistics, 26(2):205223, 2010.

22. Ayfer Ergin, İpek Eker, and Güler Alkan. Selection of container port using electre technique. Management, 4(4):268-275, 2015.

23. C. Expósito-Izquiero, E. Lalla-Ruiz, T. Lamata, B. Melián-Batista, and J. M. Moreno-Vega. Fuzzy optimization models for seaside port logistics: berthing and quay crane scheduling. In Computational Intelligence, pages 323-343. Springer, 2016.

24. Rajesh S Prabhu Gaonkar, Min Xie, and Xiuju Fu. Reliability estimation of maritime transportation: A study of two fuzzy reliability models. Ocean Engineering, $72: 1-10,2014$.

25. R.S.P. Gaonkar, M. Xie, and X. Fu. Reliability estimation of maritime transportation: A study of two fuzzy reliability models. Ocean Engineering, 72:1-10, 2013.

26. M. Ghazanfari, S. Rouhani, and M. Jafari. A fuzzy topsis model to evaluate the business intelligence competencies of port community systems. Polish Maritime Research, 21(2):86-96, 2014.

27. G. Giuliano and T. O'Brien. Reducing port-related truck emissions: The terminal gate appointment system at the ports of los angeles and long beach. Transportation Research Part D: Transport and Environment, 12:460-473, 2007.

28. M.-H. Ha, Z. Yang, T. Notteboom, A.K.Y Ng, and M.-W. Heo. Revisiting port performance measurement: A hybrid multi-stakeholder framework for the modelling of port performance indicators. Transportation Research Part E: Logistics and Transportation Review, 103:1-16, 2017.

29. S. He, R. Song, and S.S. Chaudhry. Fuzzy dispatching model and genetic algorithms for railyards operations. European Journal of Operational Research, 124:307-331, 2000.

30. S. M. Homayouni and S. Hong. A fuzzy genetic algorithm for scheduling of handling/storage equipment in automated container terminals. International Journal of Engineering and Technology, 7(6):497-501, 2015.

31. W.-K.K. Hsu, H.-F. Yu, and S.-H.S. Huang. Evaluating the service requirements of dedicated container terminals: a revised ipa model with fuzzy ahp. Maritime Policy ES Management, 42(8):789-805, 2015.

32. C.L. Hwang and K. Yoon. Multiple Attribute Decision Making: Methods and Applications. Springer, New York, 1981.

33. H. Jafari, N. Saeidi, A. Kaabi, E. Noshadi, and H. R. Hallafi. Analysis of performance in container handling operation by using fuzzy topsis method. International Review of Basic and Applied Sciences, 1(6):148-155, 2013.

34. C. Jin, X. Liu, and P. Gao. An intelligent simulation method based on artificial neural network for container yard operation. In Advances in Neural Networks ISNN 2004, Lecture Notes in Computer Science 3174, pages $904-911,2004$.

35. A. John, D. Paraskevadakis, A. Bury, Z. Yang, R. Riahihttp, and J. Wang. An integrated fuzzy risk assessment for seaport operations. Safety Science, 68:180-194, 2014.

36. A. John, D. Paraskevadakis, A. Bury, Z.i Yang, R. Riahi, and J. Wang. An integrated fuzzy risk assessment for seaport operations. Safety Science, 68:180-194, 2014. 
37. B. Ka. Application of fuzzy AHP and ELECTRE to China Dry port location selection. The Asian Journal of Shipping and Logistics, 27:331-335, 2011.

38. Y. Kayikci. A conceptual model for intermodal freight logistics centre location decisions. Procedia-Social and Behavioral Sciences, 2:6297-6311, 2010.

39. Y.H. Kim, T. Park, and K.R. Ryu. Dynamic weight adjustment for developing a stacking policy for automated container terminals. In International Conference on Intelligent Manufacturing and Logistics Systems (IML 2007), pages 26-28, Kitakyushu, Japan, 2007.

40. H.J. Ko. A dss approach with fuzzy ahp to facilitate international multimodal transportation network. KMI International Journal of Maritime Affairs and Fisheries, 1:51-70, 2009.

41. G.S. Liang, J.-F. Ding, and C.-K. Wang. Applying fuzzy quality function deployment to prioritize solutions of knowledge management for an international port in Taiwan. Knowledge-Based Systems, 33:83-91, 2012.

42. D. Liu, J. Yi, D. Zhao, and W. Wang. Adaptive sliding mode fuzzy control for a two-dimensional overhead crane. Mechatronics, 15(5):505-522, 2005.

43. W. Liu, H. Xu, and X. Zhao. Agile service oriented shipping companies in the container terminal. Transport, 24(2):143-153, 2009.

44. P. Lokuge and D. Alahakoon. Improving the adaptability in automated vessel scheduling in container ports using intelligent software agents. European Journal of Operational Research, 177:1985-2015, 2007.

45. P. Lokuge, D. Alahakoon, and P. Dissanayake. Collaborative neuro-BDI agents in container terminals. In 18th International Conference on Advanced Information Networking and Application, AINA, pages 155-158, 2004.

46. C. Mabrouki, F. Bentaleb, and A. Mousrij. A decision support methodology for risk management within a port terminal. Safety Science, 63:124-132, 2014.

47. X.-Y. Mi and G. Cheng. Railway container center door lane analysis based on -cut theory. Procedia - Social and Behavioral Sciences, 96(6):2425-2430, 2013.

48. W.C. Ng and Y. Ge. Scheduling landside operations of a container terminal using a fuzzy heuristic. IEEE Industrial Conference on Industrial Informatics, 2006.

49. A. S. Nooramin, M. Kiani, M. Mansoor, A. R. Jahromi, and J. Sayareh. Comparison of ahp and fahp for selecting yard gantry cranes in marine container terminals. Journal of the Persian Gulf (Marine Science), 3(7):50-70, 2012.

50. S. Onut, U.R. Tuzkaya, and E. Torun. Selecting container port via a fuzzy ANPbased approach: A case study in the Marmara region, Turkey. Transport Policy, 18:181-193, 2010.

51. J.-Y. Park and G.-T Yeo. An evaluation of greenness of major Korean ports: A fuzzy set approach. The Asian Journal of Shipping and Logistics, 28:67-82, 2012.

52. W. Ran, Z. Xu, and Z. Weihong. Analysis on comprehensive strength of Chinese coastal container shipping company based on genetic fuzzy clustering. In Proceedings of the IEEE International Conference on Automation and Logistics, pages 2214-2219, Qingdao, China, 2008.

53. F. Riedewald. Comparison of deterministic, stochastic and fuzzy logic uncertainty modelling for capacity extension projects of DI/WFI pharmaceutical plant utilities with variable/dynamic demand. PhD thesis, University College Cork, Ireland, 2011.

54. J. Ries, R.G. González-Ramírez, and P. Miranda. A fuzzy logic model for the container stacking problem at container terminals. In International Conference in Computational Logistics - ICCL 2014, Lecture Notes in Computer Science 8760, pages 93-111. Springer.

55. T. Saaty. A scaling method for priorities in hierarchical structures. Journal of Mathematical Psychology, 15:234-281, 1977. 
56. N. Saeidi, A. Askari, and H. Jafari. Application of a fuzzy topsis approach based on subjective and objective weights in the container terminals risks assessment. $A p$ plied Mathematics in Engineering, Management and Technology, 1(4):2013, 2013.

57. S.-M. Seyed-Hosseini and K. K. D. Fuzzy container allocation problem in maritime terminal. Journal of Industrial Engineering and Management, 2(2):323, 2009.

58. W. Shao, Y. Du, and S. Lu. Performance evaluation of port supply chain based on fuzzy-matter-element analysis. Journal of Intelligent $\&$ Fuzzy Systems, 31(4):21592165, 2016.

59. R. Stahlbock and S. Voß. Operations research at container terminals: a literature update. OR Spectrum, 30:1-52, 2008.

60. D. Steenken, S. Voß, and R. Stahlbock. Container terminal operation and operations research - a classification and literature review. OR Spectrum, 26:3-49, 2004.

61. K. Tierney, S. Voß, and R. Stahlbock. A mathematical model of inter-terminal transportation. European Journal of Operational Research, 235:448-460, 2014.

62. F. Torfi, R.Z. Farahani, and S. Rezapour. Fuzzy AHP to determine the relative weights of evaluation criteria and fuzzy topsis to rank the alternatives. Applied Soft Computing, 10:520-528, 2010.

63. D. Tuljak-Suban and E. Twrdy. Fuzzy empty containers excess estimation as an economic indicatorthe case of the north adriatic port system. Maritime Policy $\mathbb{6}$ Management, 42(8):759-775, 2015.

64. S.T. Ung, V. Williams, H.S. Chen, S. Bonsall, and J. Wang. Human error assessment and management in port operations using fuzzy ahp. Marine Technology Society Journal, 40:73-86, 2006.

65. H. Valdés-González, L. Reyes-Bozo, E. Vyhmeister, J. L. Salazar, J. P. Sepúlveda, and M. Mosca-Arestizábal. Container stacking revenue management system: A fuzzy-based strategy for Valparaiso port. Dyna, 82(190):38-45, 2015.

66. K. Vukadinović and D. Teodorovíc. A fuzzy approach to the vessel dispatching problem. European Journal of Operational Research, 76:155-164, 1994.

67. B. Wang. Research about the fuzzy optimization of repositioning of empty container on sea-bound. Port Engineering Technology, 2007.

68. Y. Wang, G.-T. Yeo, and A.K.Y. Ng. Choosing optimal bunkering ports for liner shipping companies: A hybrid fuzzy-delphi-topsis approach. Transport Policy, 35:358-365, 2014.

69. P. Wanke and B. B. Falcão. Cargo allocation in Brazilian ports: An analysis through fuzzy logic and social networks. Journal of Transport Geography, 60:3346, 2017.

70. S. Wibowo and H. Deng. A fuzzy screening system for effectively solving maritime shipping problems. Coimbra, Portugal, 2010.

71. S. Wibowo and H. Deng. Intelligent decision support for criteria weighting in multicriteria analysis for evaluating and selecting cargo ships under uncertainty. In International MultiConference of Engineers and Computer Scientists, IMECS, Hong Kong, 2011.

72. Z. Yang, A.K.Y. Ng, and J. Wang. A new risk quantification approach in port facility security assessment. Transportation Research Part A: Policy and Practice, 59:72-90, 2014.

73. Z.L. Yang, S. Bonsall, and J. Wang. Use of hybrid multiple uncertain attribute decision making techniques in safety management. Expert Systems with Applications, 36:1569-1586, 2009. 
74. S Yasunobu and T Hasegawa. Evaluation of an automatic con-tainer crane operation sys-tem based on predictive fuzzy control. Control Theory and Advanced Technology, 2(3):419-432, 1986.

75. G.-T. Yeo and D.-W. Song. An application of the hierarchical fuzzy process to container port competition: Policy and strategic implications. Transportation, 33:409422, 2006.

76. Gi-Tae Yeo, Adolf KY Ng, Paul Tae-Woo Lee, and Zaili Yang. Modelling port choice in an uncertain environment. Maritime Policy \& Management, 41(3):251267, 2014.

77. M. Yu, S. Wang, and C. Yun. A dispatching method for trucks at container terminal by using fuzzy-cnp concept. In IIEEE International Conference on Logistics Engineering and Intelligent Transportation Systems, LEITS, pages 1-4, Wuhan, 2010.

78. L.A. Zadeh. Fuzzy sets. Information and Control, 8:338-353, 1965.

79. Edmundas Kazimieras Zavadskas, Zenonas Turskis, and Vygantas Bagočius. Multicriteria selection of a deep-water port in the eastern baltic sea. Applied Soft Computing, 26:180-192, 2015.

80. E. Zehendner and D. Feillet. Benefits of a truck appointment system on the service quality of inland transport modes at a multimodal container terminal. European Journal of Operational Research, 235:461-469, 2014.

81. J.-N. Zheng, C.-F. Chien, and M. Gen. Multi-objective multi-population biased random-key genetic algorithm for the 3-D container loading problem. Computers 6 Industrial Engineering, pages 80-87, 2015.

82. P. Zhou, Kang H., and Li L. A fuzzy model for scheduling handling equipments handling outbound container in terminal. In Sixth World Congress on Intelligent Control and Automation, 2006. 